\section{HSE}

Historia Social y de la Educación

Social and Education History
Hipatia Press

www.hipatiapress.com

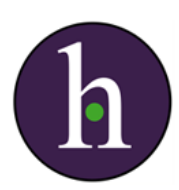

Instructions for authors, subscriptions and further details:

http://hse.hipatiapress.com

\title{
Educational memory of chinese female intellectuals in early twentieth century
}

Guo Mengna

1) Universitat de Barcelona (España)

Date of publication: June $23^{\text {rd }}, 2020$

Edition period: Edition period: June 2020-October 2020

To cite this article: Guo, M. (2020). Educational memory of Chinese Female Intellectuals in Early Twentieth Century [Review of the book]. Social and Education History 9(2), 224-226. doi:10.17583/hse.2020.5267

To link this article: http://dx.doi.org/10.17583/hse.2020.5267

\section{PLEASE SCROLL DOWN FOR ARTICLE}

The terms and conditions of use are related to the Open Journal System and to Creative Commons Attribution License (CC-BY). 
HSE - Social and Education History Vol. 9 No. 1 February 2020 pp.

224-226

\section{Reviews (I)}

Jiang, L. (2018). Educational memory of Chinese Female Intellectuals in Early Twentieth Century. Singapore: Springer

ducational Memory of Chinese Female Intellectuals in Early

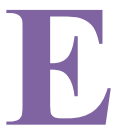
Twentieth Century describes the campus life, teacher-student interaction, academic career, and ideological change of the first generation of female intellectuals trained in higher education in China as the Chinese society changed in the early 20th century. Using the research methods of life history, oral history, and history of mentalities, the author reveals the special experiences and ideological journeys of Chinese female intellectuals by the literature works of three firstgeneration Chinese female intellectuals and other people's interpretations and commentary on their works. It also analyzes the relationship between many factors such as society, academia and education, especially higher education, and female intellectuals.

Chapter 1 is the introduction of the whole book. It explains the emergence of Chinese intellectuals, in particular, Chinese female intellectuals. The author also illustrates two essential factors that promote the transformation of traditional Chinese intellectuals into contemporary intellectuals, and states research methods.

Chapter 2 Flexible Borderline: Beijing Female Normal School in 1917 describes the architectural structure design of Beijing Female Normal School and the relationship between its design and traditional Chinese culture. After that, the author introduces the educational life of the students of Special Training Major of Chinese Literature and Language in Beijing Female Higher Normal College and compares the traditions of female education in feudal China with the educational situation of Peking University that only recruit male. The process and obstacles of Beijing Female Normal School transformed to Beijing Female Higher Normal University are also mentioned, as well as the role played by key men during this process. All of the above indicate the variability of the external environment and the 
reconstruction of social order in China, providing possibilities for social and educational changes.

Chapter 3 Diversified Traditions: Early Education Life of Female Individuals describes the early life and educational experience of three firstgeneration female intellectuals in China-- Cheng Junying, Feng Shulan and $\mathrm{Lu}$ Yin. Their early experience reveals their reasons for giving up traditional female identities and lifestyles, as well as their motivation to study. It is a very unique growth experience and life story different from the male intellectual.

In the 19th century, there were three schools of thought in the mainstream of Chinese literature academia in the 1990---Tongcheng Style, Wenxuan Style, Jiangxi Style inherited from Song Dynasty. In chapter 4 Education Situation Plagued by Academic Conflicts: Beijing Female Higher Normal College During May Fourth Movement, since $\mathrm{Hu}$ Shi proposed literary reform, the concept of orthodox literature ideas began to be criticized at the end of 1916, and two Chinese literature masters coming to the Special Training Major of Chinese Literature and Language of Beijing Female Normal School in August 1918 proposed to "carry on extinct studies and support marginal studies". But this cannot stop the rejection of the new trend of thought. The reform of Chen Zhongfan and the emerging of intellectuals such as Hu Shi and Li Dazhao not only contributed to the establishment of a modern academic education system, but also provided indispensable conditions for the generation of Chinese female intellectuals.

In Beijing Female Higher Normal College, the three female intellectuals underwent the impact of traditional Chinese learning and new culture, revolutionists and reformists. Their obedience and stubborn abidance to traditions and authority were replaced by independent choice-making rights. Chapter 5 Seeking for and Recognizing the New Identity: Female Individual's Transmutation and Rebirth deeply describes the transformation of three females, Cheng Junying, Feng Yuanjun (Feng Shulan), and Lu Yin, in Beijing Female Higher Normal College and their academic interaction with the teacher. Meanwhile, the three female intellectuals also gradually found their true vocation and the "irreplaceable" inner aspiration and interest through constant attempts and exploration under the intricacies of influences.

Although the three Chinese female intellectuals' early experiences and specific careers are different, they all "had the responsible sense of 'mission in life' inherited from Chinese traditional culture or inspired by the society behind their personal interest and pursue". Chapter 6 Scholars and 
Academia: Female Individuals' Long Journeys for Gentry introduces the educational life, academic life and family life of the three female intellectuals after they left the campus. In this period, they have encountered harsh life and challenges, but the spirit which transcends personal interest and considers culture inheritance as personal responsibility has driven them to move forward.

This book shows the changes in thoughts and interests experienced by three Chinese female intellectuals with the changes of the broad social context. At the same time, it also tries to show the special role played by higher education in promoting academic transformation and establishing a modern academic education system.

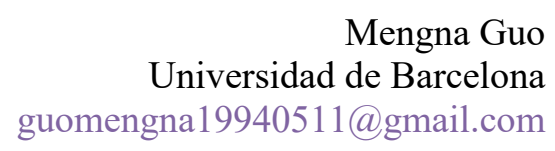

